\title{
Cenografias do trabalho docente de orientação em tempos de práticas mercantilistas: sobredestinatário e posicionamento discursivo
}

\author{
Scenographies of supervision as a teaching practice in the time of \\ merchant practices: the superaddressee and discursive positioning
}

\author{
Décio ROCHA*
}

Universidade do Estado do Rio de Janeiro (UERJ/CNPq)

\begin{abstract}
RESUMO: Tomando por base textos humorísticos que circulam na internet versando sobre a relação instituída entre os participantes do trabalho de orientação de pesquisas acadêmicas, este artigo tem por objetivo explicitar o afrontamento de duas posições discursivas referentes ao trabalho acadêmico na contemporaneidade: uma posição de alinhamento às políticas neoliberais e uma posição crítica de afastamento em relação a essas políticas. Para tal fim, recorre-se à articulação das noções de cenografia (MAINGUENEAU, 1989) e sobredestinatário (BAKHTIN, 1992), as quais fornecerão pistas para a depreensão dessas posições discursivas, além de permitir lançar algumas hipóteses sobre a produção de subjetividade no referido contexto.
\end{abstract}

PALAVRAS-CHAVE: Trabalho docente de orientação. Políticas neoliberais. Cenografia. Sobredestinatário. Posicionamento.

ABSTRACT: Based on humorous texts circulating on internet dealing with the relationship established in the work of supervising of academic research, this paper aims at exploring the clash of two discursive positions in academic work in contemporary world: a position of alignment to neoliberal policies and a critical view of deviation from these policies. To achieve our goal, we had recourse to the articulation of the concepts of scenography (MAINGUENEAU, 1989) and superaddressee (BAKHTIN, 1992), which provide important clues to the apprehension of these discursive positions and enable us to launch some assumptions about the production of subjectivity in the context of neoliberal education.

KEYWORDS: Teaching practice of supervision. Neoliberal policies. Scenography. Superaddressee. Positioning.

\section{Introdução: revisitando o sentido de algumas práticas acadêmicas}

As políticas para a educação superior no Brasil vêm descrevendo uma trajetória inquietante, tendo em vista o crescente privilégio de ligações funcionais e pragmáticas dos trabalhadores com seu processo de trabalho ${ }^{1}$. Produtividade, competência, autonomia e competitividade instituem-se no mercado de saberes como palavras de ordem que vêm

\footnotetext{
* Doutorado em Linguística Aplicada; professor Associado da Universidade do Estado do Rio de Janeiro (UERJ), Instituto de Letras e Instituto de Aplicação. Membro do GT-Anpoll Linguagem, Enunciação e Trabalho e também dos grupos de pesquisa Atelier e PraLinS (CNPq). É bolsista do CNPq e da FAPERJ. Rio de Janeiro - RJ - Brasil. E-mail: rochadm@uol.com.br.

${ }^{1}$ Em artigo publicado há 8 anos, o autor já se voltava para o caráter preocupante da referida modalidade de trabalho docente. Ver Rocha \& Rocha (2004).
} 
gerando como efeitos o isolamento, a fragmentação e o tédio no cotidiano das práticas acadêmicas.

Diante de tal quadro, meu objetivo neste artigo é explicitar um possível caminho de reflexão sobre questões ligadas ao trabalho acadêmico na universidade, recorrendo para tal a uma perspectiva enunciativa das práticas de linguagem. Por intermédio de uma leitura renovada das referidas práticas acadêmicas à luz de uma abordagem discursiva, pretendese promover um sentido ético para as questões levantadas, na medida em que, longe de se buscar qualquer sistema de verdades, o que se espera é favorecer novos encontros na escuta das diferenças que se fazem em nós, atores da cena educacional, com a consequente afirmação de novos devires.

O artigo está organizado em cinco momentos: no primeiro, recorro a dois textos humorísticos que circulam na internet tematizando as práticas de orientação acadêmica na universidade; em (2), apresenta-se um panorama geral das políticas neoliberais para a educação superior; em (3), introduz-se uma reflexão baseada na perspectiva dialógica da linguagem, tendo em vista o objetivo de proceder a uma leitura das relações entre pesquisadores (docentes e estudantes) na universidade; a seguir, em (4), articulo as noções de cenografia e sobredestinatário, desenvolvidas, respectivamente, por Dominique Maingueneau (1989) e Mikhail Bakhtin (1992), considerando a aposta que se faz na produtividade de tal encontro conceitual para a problematização das condições sob as quais se dá a produção de conhecimento na atualidade; um último tópico intitulado (in)conclusões tematizará a diversidade de caminhos que vêm sendo experimentados para a operacionalização do conceito de sobredestinatário, reflexão que deixará em aberto a responsabilidade de todos diante da opção entre fortalecer ou mitigar os efeitos das práticas neoliberais em nosso cotidiano.

\section{Os dez mandamentos e as mil e uma noites do trabalho acadêmico}

A presente reflexão sobre as condições que regem na atualidade a produção de conhecimento na academia será introduzida por breves textos de caráter humorístico que vêm circulando na internet nos últimos tempos. Contados sob a ótica do trabalho acadêmico cotidiano e em anonimato, esses textos parecem ser capazes de dizer algo acerca de alguns dos impasses vividos na atualidade em relação ao tema abordado, razão pela qual os reproduzo a seguir:

(1) Texto 1 - Os dez mandamentos do orientando (SCOTT, 2004, p.168).

1. Amarás o teu orientador(a) sobre todas as "coisas";

2. Refarás teu texto quantas vezes forem necessárias;

3. Lerás bastante. Usarás a internet com bom senso, visão crítica, postura e moderação;

4. Não copiarás;

5. Prestarás atenção na concordância de gênero, número e grau;

6. Não serás prolixo. Não duvidarás da cultura geral da banca examinadora;

7. Não repetirás a mesma ideia em diferentes trechos do texto;

8. Usarás a mesma pessoa verbal do começo ao fim do texto;

9. Circunscreverás teu tema a um contexto definido. Serás claro naquilo que estás querendo expor. Estarás escrevendo para terceiros que não obrigatoriamente sabem do que se trata;

10. Não farás dos resultados obtidos as conclusões da pesquisa. Não atrasarás a entrega da versão final. Darás tempo suficiente para a leitura do orientador(a). 
(2) Texto 2 - O orientador e a lâmpada maravilhosa (SCOTT, 2004, p.168-169)

Três sujeitos caminhando lado a lado, na hora do almoço: o orientador, o bolsista de pósgraduação e o bolsista de graduação. De repente, eles veem uma lâmpada velha, dessas bem antigas, das mil e uma noites.

O orientador pega a tal lâmpada e dá uma esfregadinha com a mão ... Logo aparece uma fumaceira e sai um Gênio, daqueles grandes, logo dizendo:

- Normalmente eu concedo três desejos, mas já que vocês são três, um para cada um ...

O bolsista de graduação gritou:

- Primeiro eu, primeiro eu! Gênio, quero ir para as Bahamas, ficar por lá com uma escrava sexual colocando uvas na minha boca, à beira da piscina do melhor hotel que tiver por lá e sem nenhum tipo de preocupação monetária ou de saúde.

Buum! O cara desapareceu.

- Agora eu, gritou o bolsista de pós-graduação. Seu Gênio, me manda para Honolulu. Quero duas gatas dessas bem gostosas para me acompanhar, ficar fazendo surf o ano inteiro, só coçando o saco e cheio de piña colada pra tomar, à vontade mesmo.

Bum! Lá foi o cara embora para os mares do sul.

Então o Gênio falou para o orientador:

- Agora, você!

Diz o orientador:

- Quero esses dois de volta, no laboratório, depois do almoço.

Moral da história: sempre deixe o orientador falar primeiro.

Reconhece-se logo de início que, afinal, não é qualquer parcela da população que faria humor com as condições nas quais se dá o trabalho acadêmico, em especial o trabalho acadêmico voltado para a atividade de pesquisa e, portanto, de produção de conhecimento. Com isso, quero dizer que esses dois textos só podem ter sido pensados por (e endereçados a) alguém que viva em seu cotidiano os impasses e as dificuldades do trabalho acadêmico, alguém que seja sensível a seus êxitos e fracassos; alguém, enfim, que, de alguma forma, se proponha a contar a sua própria história, falando de suas próprias inquietações. Neles, assiste-se à encenação de algo que é bastante familiar àqueles que se veem envolvidos em atividades de pesquisa e que muitas vezes se debatem maniqueisticamente entre dois extremos, apresentados como as únicas saídas possíveis: o laxismo (abandonar tudo e ir para o Havaí ou para as Bahamas, vistos como espaços paradisíacos de prazer) ou o rigorismo (permanecer no laboratório, dando continuidade ao trabalho científico e sofrendo todas as coerções impostas pela lógica subjacente a tal atividade). Com efeito, a dupla cena instituída se deixa apreender em diversos planos em cada um dos textos:

- no plano dos atores, atualiza-se, no texto 1 , a força da moralidade que submete uma das partes (o orientando) ao poder discricionário da outra (o orientador); no texto 2, a lógica do "salve-se quem puder", na qual a precipitação e o hedonismo dos orientandos, em atitude de franca competição para saber quem será o primeiro a ter seus desejos atendidos, são marcas que se contrapõem à aparente tolerância e paciência do orientador;

- no plano espacial, o texto 1 reafirma com exclusividade o enclausuramento do orientando, aprisionado nas grades do mundo acadêmico pelo "pacto" de obediência que faz com o orientador; no texto 2, produz-se o afrontamento dos espaços abertos que prometem liberdade e prazer, representados pelo repouso à beira da piscina ou pelo surfe nos mares do sul (o Havaí foi transferido para o hemisfério sul?!), contra os espaços fechados e opressivos, representados pelas quatro paredes do laboratório, onde a vida parece não acontecer; 
- no plano temporal, o texto 1 apresenta-se igualmente monológico, privilegiando tão somente um futuro que se estende ad infinitum, caracterizado pela atitude de franca submissão que será preciso manter; no texto 2, opõe-se um tempo distendido e ocioso do "não fazer nada" ao tempo regulado, cadenciado, que prevê um "antes" e um "depois" do "horário de almoço", momento de corte no árduo trabalho que tem lugar no interior do laboratório.

Como pensar essas histórias de conflito entre interesses divergentes, de silenciamentos ou de sabotagens e tentativas malogradas de fuga diante daquilo que gera desconforto? Afinal, se anedotas como essas circulam, devemos entendê-las como sintomas de uma situação que não vai bem, ou que, pelo menos, merece ser repensada ${ }^{2}$. Como caracterizar a atividade de pesquisa e de produção de conhecimento na atualidade? O que é que vem dissociando trabalho acadêmico de pesquisa, de um lado e, de outro, prazer e ética, tal como se apresenta no imaginário das anedotas relatadas? O que, afinal, vai mal e nos conduz a essa atitude de submissão e de renúncia à produção de vida, impedindo-nos de "surfar no laboratório"?

\section{Uma breve caracterização da educação como prática mercantil}

Tendo em vista a moral da segunda história que compõe o córpus escolhido, não é difícil supor a existência de uma crise na educação superior brasileira, uma crise que se atualiza como efeito do processo de mercantilização da sociedade contemporânea, com a hegemonia de uma lógica do capital que, ao reger a reestruturação dos espaços sociais, também invade as reformas propostas para as universidades. Longe de caracterizar a referida crise como uma "conspiração privatista", como a qualificam vários críticos na atualidade, Silva Júnior e Sguissardi (1999, p. 44) a entendem como uma outra direção de expansão do capital que reorienta o setor de serviços, implicando uma nova racionalidade na educação superior brasileira.

O sentido de modernização da administração pública que vem sendo produzido no âmbito do projeto de reforma iniciado no governo Fernando Henrique Cardoso privilegia as ideias de eficiência e descentralização. Com efeito, a autonomia institucional prevê que as universidades do Estado sejam transformadas em organizações sociais - entidades que assumem um contrato de gestão com o poder executivo e solicitam autorização do poder legislativo para fazer parte do orçamento público - controladas por contratos de gestão, implantando-se uma lógica de estruturação e um modo de funcionamento semelhantes à lógica de prestação de serviços para o mercado. Desse modo, constrói-se eficientemente o processo de privatização que vem sendo aconselhado pelos órgãos internacionais para as instituições públicas: para além de eventuais investimentos do Estado, o ensino superior se veria diante da obrigatoriedade de captar recursos para a sobrevivência de algumas de suas atividades, principalmente a de pesquisa, fortalecendo seus vínculos com os princípios e referenciais de mercado:

Os recursos para o setor privado originar-se-iam das anuidades e eventualmente do Estado (em função do "mérito" atribuído pelo sistema de avaliação oficial); [...] e os do setor estatal, do Estado, das anuidades e, com gradativa maior participação, do mercado (SILVA JÚNIOR; SGUISSARDI, 1999, p. 54, grifo do autor).

\footnotetext{
2 A esse respeito, ver Rocha \& Deusdará (2011).
} 
Segundo a ótica dos autores, um tal regime de estruturação e de gestão do ensino superior vem sendo responsável por estabelecer precários planos de carreira, baixo ganho salarial, política de adicionais de salário e dissolução dos laços entre ensino, pesquisa e extensão, situação que demanda um esforço suplementar no que concerne ao fortalecimento dos movimentos de resistência, à unificação das lutas no movimento docente e da pauta de reivindicações pela democratização e qualidade da educação superior. Com efeito, é preciso combater a referida modalidade de política educacional, cuja ação, na atualidade, tem na avaliação uma de suas ferramentas mais contundentes:

A avaliação [...] tem sido um dispositivo central na implementação deste novo perfil estatal [gestor portador de uma racionalidade empresarial], no campo da educação superior. A literatura analisada permite-nos afirmar que a avaliação da educação superior é incrementada num contexto de racionalização de recursos públicos, o que implica uma completa redistribuição de funções entre o centro e a periferia, de tal modo que o centro mantém o controle estratégico global através de precisos estratagemas político-avaliativos, cabendo às instituições decidir como responder às expectativas governamentais (MANCEBO; ROCHA, 2002, p. 65).

A cultura da avaliação na universidade brasileira, em consonância com as políticas neoliberais, implica o aprimoramento do racionalismo cientificista consolidado ao longo da era moderna: conhecimento técnico, objetividade, princípios ligados a leis naturais, parâmetros (pretensamente) neutros e universais. Reafirmam-se, desse modo, os dispositivos empresariais da livre concorrência na oferta dos serviços, do lucro e da competitividade, fragilizando-se a ética pública e as ações coletivas dos movimentos sociais. No referido contexto, investe-se em uma dada forma de organização do trabalho, "fator mágico que poderá resolver todas as mazelas nacionais, inclusive o crescente fosso na distribuição de renda entre os diversos estratos sociais, sendo a educação apresentada como solução" (ROCHA; ROCHA, 2004, p. 21). Tal modo de funcionamento não poderá deixar de exercer sua ação sobre os modos de subjetivação, como o evidenciam Mancebo \& Rocha (2000, p.157):

\begin{abstract}
A ênfase no individualismo e na competitividade, tomados como ingredientes necessários ao bom desenvolvimento da aprendizagem, o pragmatismo traduzido por tarefismo utilitário e tomado como a real produção acadêmica, a concepção dos estudantes como consumidores em necessária e permanente competição são somente alguns aspectos, dos mais visíveis e dolorosos, dessa 'moderna' ordenação.
\end{abstract}

Para uma apreensão dos modos de subjetivação que vêm ganhando consistência nas formas de organização do trabalho docente nas universidades, devemos nos voltar para alguns dos efeitos da lógica empresarial atravessada nas concepções de eficiência, produtividade, autonomia e hierarquia. No momento, tendo em vista a natureza dos dois textos escolhidos para leitura, apresentados no item anterior, não se aprofundará a reflexão sobre os temas da eficiência, da produtividade e da autonomia ${ }^{3}$, voltando-se exclusivamente a atenção para o investimento em dispositivos de hierarquização. Com efeito, a hierarquização investe fortemente na abolição das solidariedades coletivas, incentivando práticas de individualização, objetivos individuais, avaliação (individual) permanente, aumentos individualizados de salários ou concessão de prêmios de acordo com a competência e o mérito

\footnotetext{
${ }^{3}$ Para uma abordagem desses três temas, remeto o leitor para Rocha \& Rocha (2004).
} 
individuais, carreiras individualizadas, estratégias de "responsabilização" que buscam assegurar a autoexploração, exigência de "autocontrole" que investe na "implicação" dos assalariados segundo as técnicas da "gestão participativa". A esse respeito, retomemos a reflexão de Bourdieu (1998, p.2):

\begin{abstract}
A instituição prática de um mundo darwinista de luta de todos contra todos, em todos os níveis da hierarquia, que encontra as dinâmicas da adesão à tarefa e à empresa na insegurança, no sofrimento e no stress, não poderia triunfar tão completamente se não contasse com a cumplicidade das disposições precarizadas que produzem a insegurança e a existência, em todos os níveis da hierarquia, e mesmo nos níveis mais elevados, especialmente entre os técnicos superiores, de um exército de reserva de mão de obra docilizada pela precarização e pela ameaça permanente do desemprego.
\end{abstract}

Aproximando a problemática ora abordada à perspectiva bakhtiniana da linguagem, que será introduzida no próximo item, refletiremos sobre o sentido da ação na educação superior contemporânea - uma ação que tem sido marcada pela aceleração dos processos de mudança, gerando a segregação, a precarização e o adoecimento no trabalho docente, que se traduzem em sintomas como as ausências, o cansaço, a tensão e o tédio.

\title{
3 Para uma abordagem dialógica das práticas de linguagem
}

Se é verdade que a instantaneidade e a aceleração remetem a regimes de tempo que podem ser plenamente compatíveis com a produção de diferentes ordens de saber, também parece certo que tais regimes de tempo não são os mais favoráveis à produção de conhecimento na academia. Nesse sentido, é preciso reconhecer que nos vemos diante de um desafio: como oferecer resistência a uma tal prática hegemônica de temporalidade acelerada oriunda dos gabinetes que parece impedir a plena consecução de objetivos visados pela produção do saber acadêmico?

Para pensar algumas das marcas da referida produção de saber, recorro a Bakhtin (1992), em especial no que concerne à reflexão do autor sobre o que torna possível o fazer científico em ciências humanas. Com efeito, sua posição toma por base o primado do texto como condição de realização de qualquer atividade de pesquisa na área:

Quando o homem é estudado fora do texto e independentemente do texto, já não se trata de ciências humanas (mas de anatomia, de fisiologia humanas, etc.). (BAKHTIN, 1992, p. 334)

Tendo em vista a opção que ora faço por Bakhtin (1992), seguem quatro posiçõeschave defendidas pelo autor que nortearão a presente reflexão:

i. o homem só pode ser apreendido no interior de um texto, ou seja, é impossível, segundo a perspectiva bakhtiniana, apreender o homem fora de situação, fora de seu lugar de produção e engendramento - o social. Acrescente-se ainda que a apreensão do homem por intermédio do texto significa a impossibilidade de estudar o homem fora de uma situação de interlocução. Nesse sentido, a palavra - entenda-se, a palavra situada e dirigida a um outro - é uma necessidade incontornável de uma abordagem do homem no campo das ciências humanas: "A compreensão é o cotejo de um texto com os outros textos. [...]. O texto só vive em contato com outro texto (contexto)" (BAKHTIN, 1992, p. 404). 
ii. no âmbito das ciências humanas, o homem é um "objeto falado" (por outros) e, simultânea e principalmente, um "objeto falante" (AMORIM, 2001, p. 187). Com efeito, se dizemos que uma pesquisa em ciências humanas trabalha sobre um objeto que se deseja conhecer, isso é tão somente uma forma de expressão que deixa de explicitar sua distância em relação a objetos (tidos como naturais) como a chuva ou a neve.

Emudecer o outro, reificá-lo, tornando-o literalmente objeto do conhecimento, é, sob a ótica dos estudos bakhtinianos, sair da esfera das ciências humanas, posto que significa recusar-se a ouvir o texto do outro, ou recusar-se a ouvir o outro enquanto texto (ROCHA; ROCHA, 2004, p. 24-25).

Assim, lidar com o objeto de estudo das ciências humanas é dar voz a um sujeito e, de certo modo, com ele dividir a autoria de um novo texto que se produz com base nos saberes resultantes de tal interlocução - saberes que só existem por intermédio da escuta desse outro:

[...] lidar com objetos ou com algo que foi objetivado são posições não coincidentes: no primeiro caso, a distância entre pesquisador e campo é constitutiva da atitude epistemológica que se assume (fala-se de um ele que se presume existir fora da relação com o pesquisador); no segundo, reconhece-se desde o início o território de pesquisa como um campo de experiências complexo, já que pressupõe considerar a multirreferencialidade que dá corpo aos fatos e acontecimentos, envolvendo, portanto, contextualização e análise das implicações entre pesquisador-pesquisado (fala-se, portanto, a um você com o qual se compartilha a produção de um dado saber) (ROCHA; ROCHA, 2004, p.25).

É nesse sentido que os autores se referem, então, a um "pacto de interlocução”, segundo o qual "eu e você, enquanto posições reversíveis, tornam possível a produção de um ele do qual se decide falar” (ROCHA; ROCHA, 2004, p. 25).

iii. o homem se constrói na interlocução como algo que lhe é constitutivo, e não como uma escolha que se faz ou como um ideal que se busca alcançar.

O diálogo não é o resultado de um ato deliberado de abertura ao outro, mas, pelo contrário, resulta da impossibilidade de nos fecharmos diante da alteridade. Não escolhemos abrirmo-nos para a alteridade dialógica. Ela nos afeta antes mesmo de vivermos e de agirmos no mundo. Ela é inalienável ${ }^{4}$ (PONZIO, 1998 CLOT, 2005, p. 4, tradução nossa).

iv. para além de um eu e de um você, partícipes da interação verbal, há de se contar com a presença de um terceiro, igualmente fundamental para o curso da interação, que Bakhtin denomina sobredestinatário (em russo, nadadresat): "compreender é, necessariamente, tornar-se o terceiro num diálogo" (BAKHTIN, 1992, p. 355). Por intermédio da noção de sobredestinatário, compreende-se que "em sua busca de uma compreensão responsiva, a palavra sempre vai mais longe" (BAKHTIN, 1992, p. 357), ou seja, compreende-se que o outro (o sobredestinatário "invisível") a quem sempre se fala está efetivamente situado para além das evidências da situação empírica, como bem o atestam as diferentes identidades ideológicas concretas que

\footnotetext{
${ }^{4}$ On ne choisit pas de s'ouvrir à l'altérité dialogique. Elle nous affecte avant même de vivre et d'agir dans le monde. Elle est insupprimable.
} 
ele é capaz de assumir (Deus, a verdade absoluta, o julgamento da consciência humana imparcial, o povo, o julgamento da história, a ciência, etc.).

O autor nunca pode entregar-se totalmente e entregar toda a sua produção verbal unicamente à vontade absoluta e definitiva de destinatários atuais ou próximos [...] e sempre pressupõe (com maior ou menor consciência) alguma instância de compreensão responsiva que pode estar situada em diversas direções. Todo diálogo se desenrola como se fosse presenciado por um terceiro, invisível, dotado de uma compreensão responsiva, e que se situa acima de todos os participantes do diálogo (os parceiros). [...] O fato decorre da natureza da palavra que sempre quer ser ouvida, busca a compreensão responsiva, não se detém numa compreensão que se efetua no imediato e impele sempre mais adiante (de um modo ilimitado) (BAKHTIN, 1992, p. 356).

Tendo em vista o que acima ficou exposto, parece lícita a tentativa de distinguir traços determinantes de duas funções (certamente complementares) exercidas por esse coenunciador:

- por um lado, o sobredestinatário seria alguém capaz de responder de forma ativa e em sintonia com o enunciado, compreendendo-o exatamente como é preciso: "Cada diálogo se dá contra o plano de fundo da compreensão responsiva de uma terceira parte invisivelmente presente que está acima de todos os participantes do diálogo" (MORSON; EMERSON, 1990, p. 151);

- por outro lado, o sobredestinatário é visto como sendo a instância que exerce a "pressão de uma semiose infinita [...] sobre um enunciado particular, a possibilidade sempre disponível de que o enunciado seja compreendido de outro modo." (FARMER, 1997, p. 85-86). O referido descolamento da palavra em relação a uma dada situação é o que garante, por exemplo, que uma obra literária possa apresentar um interesse não apenas imediato, sendo efetivamente lida por um leitor não previsto (um público não contemporâneo do autor, ou não pertencente a sua comunidade imediata); eis, desse modo, o que garante que um texto seja acolhido por um público que, ainda que imediato e contemporâneo, não seja o público de origem previsto pelo autor (como ocorre no caso de textos produzidos para fins específicos no interior de uma dada coletividade e dos quais se apropria o pesquisador para outros fins, transformando-os em córpus de sua pesquisa).

Acrescentemos ainda a contribuição deixada por Clot (2005) no que diz respeito a um último tópico: a natureza tríplice de todo e qualquer diálogo, tendo em vista a presença do destinatário, do sobredestinatário e do subdestinatário, conceito utilizado pelo autor para se referir às vozes que se atualizam no diálogo interior:

É precisamente a luta pelo objeto que explica [...] a existência de três diálogos em um. Acontece que, nas réplicas do diálogo com o destinatário imediato, dois outros diálogos se fazem ouvir: o "grande diálogo" com o terceiro participante invisível e o "pequeno diálogo" consigo mesmo. Dito de outra forma, dirigidas ao(s) destinatário(s) imediato(s), as réplicas são simultaneamente perguntas e respostas ao sobredestinatário e ao subdestinatário [...] (CLOT, 2005, grifo do autor, p. 3-4).

Tendo em vista o recurso a Bakhtin (1992) no sentido de se repensar de que modo vem-se construindo a interlocução entre a universidade e as vozes que dão sustentação a políticas neoliberais em educação, qual a vantagem da noção de sobredestinatário para o 
referido debate? Por intermédio da análise de alguns dos dispositivos que vêm ritmando as condições nas quais tem lugar a produção de conhecimento na universidade, procurarei oferecer no próximo item uma possível resposta à questão formulada.

\section{Cenografia e sobredestinatário: definindo posicionamentos discursivos}

A produção de conhecimento na universidade compreende hoje uma vasta gama de atividades, sendo possível elencar minimamente o trabalho realizado em sala de aula, a pesquisa, os trabalhos de iniciação científica, a orientação em pós-graduação, a escritura e publicação de livros e artigos científicos, a participação em bancas examinadoras de conclusão de curso (monografias de graduação, dissertações de mestrado, teses de doutorado), etc. Trata-se de atividades que não se exercem da mesma forma e que não possuem todas 0 mesmo reconhecimento enquanto produção de conhecimento, nem colocam todas em cena os mesmos coenunciadores.

Privilegia-se neste artigo o trabalho de orientação acadêmica, segundo se depreende dos textos escolhidos para análise - os dez mandamentos do orientando e o gênio da lâmpada. Ambos são ritmados por uma lógica que transforma a produção de conhecimento em mera "administração de dados e informações em um processo de assessoramento ao mercado", para retomar a reflexão de Silva Júnior e Sguissardi (1999, p. 54). Tal lógica ganha corpo em muitos dos dispositivos de implementação do trabalho acadêmico e, em especial, no que se refere aos processos mais ou menos regulares de avaliação institucional sobre os quais pesam critérios de eficiência, de competitividade, de redefinição de categorias como as do público e do privado, implicando a ressignificação da expressão "autonomia universitária" e o investimento na meritocracia: necessidade de manutenção de uma certa regularidade no ritmo de produção, ritmo que é preciso que o pesquisador respeite (por exemplo, na entrega de relatórios parciais e finais de pesquisa, no agendamento de encontros periódicos com orientandos, no preenchimento de formulários diversos, planos de curso), sob pena de punição na hipótese de tarefas ou prazos não cumpridos.

De que modo vem-se constituindo o diálogo entre a universidade e as vozes que se atualizam nas políticas neoliberais? Que articulações podemos depreender por intermédio de uma abordagem das práticas de linguagem no que diz respeito ao cotidiano do trabalho docente, em especial no que se refere às relações entre orientador e orientando e a produção de subjetividade que nessas relações se atualiza? Para ensaiar uma resposta, faço a opção por uma leitura de nosso córpus tendo como recurso as noções de cenografia (MAINGUENEAU, 1989) e sobredestinatário (BAKHTIN, 1992).

O córpus escolhido constitui-se de textos de humor de diferentes naturezas: o primeiro é feito para ser lido, ao passo que o segundo assume uma forma de história humorística cuja narração se dará preferentemente na modalidade oral. Ambos colocam em xeque questões ligadas à execução de um trabalho acadêmico (seja ele a dissertação de mestrado ou a tese de doutorado, seja o trabalho de pesquisa em laboratório), assim como a definição de um certo modo de produção de subjetividade.

Se retomarmos os dois traços por intermédio dos quais buscamos caracterizar o sobredestinatário - a saber, a compreensão / resposta adequadas ao que é dito e a garantia de que públicos diversos (no tempo e no espaço) poderão ressignificar o texto -, então poderemos lançar uma hipótese sobre a configuração do(s) sobredestinatário(s) produzido(s) nesses dois textos.

Antes, contudo, vale pensar o perfil do destinatário. Este só poderá ser alguém capaz de apreender o que há de humor nesses textos, isto é, alguém que não se deixe capturar pelo plano das cenografias (MAINGUENEAU, 1989, 2001) neles instituídas e que consi- 
ga, pois, distingui-lo do plano das coerções genéricas. Explico-me. Ao pensar a cena enunciativa com Maingueneau (2001), cumpre distinguir inicialmente uma dupla configuração: o quadro cênico (formado pelas cenas englobante e genérica) e a cenografia. Esta, segundo o autor, funciona como uma espécie de cilada, pois o que ela faz, com o objetivo de instituir uma cena de enunciação legitimante, é encobrir o quadro cênico. Eis precisamente o que se verifica nos dois textos que compõem o córpus deste artigo: o primeiro texto, apresentado com uma "roupagem" de decálogo, e o segundo, travestido de conto maravilhoso, são, na realidade, piadas (ou histórias humorísticas). Em outras palavras, o gênero "histórias de humor" apresenta-se ao leitor travestido pelas cenografias de decálogo e de conto maravilhoso.

Quando digo que o destinatário desses textos deve ser alguém que não se deixe capturar pelas cenografias instituídas, quero assegurar que esse destinatário logrará alcançar o humor que se manifesta por intermédio do gênero de discurso (piada ou história de humor). Com efeito, um leitor que levasse a sério as duas cenografias instituídas perderia o acesso ao plano de comicidade dos textos: no caso de texto 1, isso ocorreria na hipótese de, estando familiarizado com a tradição judaico-cristã e, portanto, sendo capaz de reconhecer um intertexto como os dez mandamentos, tomasse como séria a iniciativa de oferecer ao orientando as regras que garantiriam seu sucesso no trabalho acadêmico; no caso do texto 2, o mesmo ocorreria com um leitor que, familiarizado com a tradição literária dos contos populares originários do Oriente Médio e do sul da Ásia, compilados em língua árabe a partir do século IX, não superasse a cenografia de narração de conto maravilhoso.

Uma vez definido um perfil de destinatário para os textos em questão, passemos ao levantamento de hipóteses acerca de seu(s) sobredestinatário(s). Trata-se de etapa relevante na apreensão dos efeitos de sentido desses textos, uma vez que ao sobredestinatário cabe minimamente, como vimos, uma dupla função: por um lado, propiciar uma compreensão sempre adequada do enunciado proferido; por outro, garantir uma semiose ilimitada, isto é, a multiplicação de leituras do enunciado por públicos diversos (distantes no tempo e/ou no espaço). No caso dos dois textos em questão, que imagem(ns) de sobredestinatário se con$\operatorname{voca}(m)$ nesses textos? Como definir esse(s) sobredestinatário(s) a partir da dupla função que ora menciono?

Partindo do entendimento de que não faria sentido considerar como destinatário desses textos alguém que se deixasse imobilizar pela cenografia, caracterizando-se minimamente o destinatário como aquele que é capaz de receber os textos como "histórias de humor”, não se pretende dizer que a compreensão das piadas só possa se fazer em uma via de mão única. Ao contrário, dois parecem ser os caminhos possíveis de serem percorridos pelo interlocutor para chegar ao efeito de humor das duas histórias. Os referidos caminhos serão definidos em função do modo como se apreende a cenografia desses textos e, como se justificará a seguir, explicitarão posições distintas de sobredestinatário.

Uma primeira atitude diante do humor de Os dez mandamentos e O orientador e a lâmpada maravilhosa consiste em rir fazendo pouco caso das cenografias, isto é, explicitando o absurdo de uma atitude como a do locutor do decálogo, que subestima os problemas de execução de um trabalho monográfico (dissertação ou tese), encontrando a simplória solução que consiste em decretar leis a que o orientando deverá obedecer; ou como na história do gênio da lâmpada, da qual se ri principalmente pela subversão imposta à cenografia: a lâmpada mágica, que representava uma solução segura no conto de Aladim, revela-se agora como uma saída nem um pouco confiável, uma vez que pode tanto favorecer quanto obstaculizar os desejos dos personagens. Assim, ao se menosprezar o dispositivo cenográfico como solução, assume-se que o humor se deve sobretudo à inadequação desse dispositivo que prevê "saídas mágicas" para problemas sérios como o da qualidade de tra- 
balho de um pós-graduando ou o das condições de trabalho em um laboratório de pesquisa: questões como o tédio, o excesso de trabalho e o talento para a vida acadêmica, que são preocupantes na contemporaneidade, não podem ser resolvidas por meio de soluções como as sugeridas ${ }^{5}$.

Uma outra atitude diante das mesmas histórias consiste em rir da situação cômica, dando, porém, crédito às cenografias escolhidas para a produção do efeito de humor. O que estamos chamando de "dar crédito às cenografias"? Em poucas palavras, dar crédito às cenografias significa tomá-las como coisa séria, atribuindo a alguma outra instância a origem do efeito de humor produzido. Diferentemente da atitude descrita no parágrafo anterior, não são as cenografias que, inapropriadas, provocam o riso; agora, o que faz rir é a conivência com uma certa "esperteza" do orientador, provável mentor das cenas de humor em ambas as histórias, que sempre consegue tirar bom proveito das situações: no texto 1 , esse orientador estabelece um "passo a passo do bom orientando", reafirmando a atitude de obediência que este deverá manifestar ao longo de todo o seu processo na academia; no texto 2, pela reflexão e paciência de que dá provas, sabe esperar o momento exato para interferir na história, obtendo êxito em trazer de volta os dois orientandos demissionários. Essa aliança com a posição discursiva do enunciador-orientador corresponde à posição de quem entende que somente o recurso a expedientes extremos como o estabelecimento de "leis" a serem obedecidas pelo orientando, ou o passe de mágica proporcionado pelo gênio da lâmpada, são saídas eficientes para resolver o problema colocado, tal é o despreparo dos orientandos na atualidade para cumprirem satisfatoriamente suas funções. Assim é que o riso se explica pelo desnudamento de tudo aquilo que o orientando traz como falta: não é capaz de escrever, copia de forma acrítica textos da internet, não cumpre prazos, não se esforça e deseja facilidades no trabalho, etc. A referida aliança com esse "orientadormarionetista” implicará uma ratificação de seu ponto de vista, já que ele tem sucesso na recuperação de seu "orientando-marionete"6.

A cada uma das duas posições apresentadas relacionaremos uma posição de sobredestinatário, entendido como essa terceira posição ocupada por quem é sempre capaz de uma compreensão responsiva adequada e, como responsável pelo processo de semiose ilimitada, promove leituras sempre renovadas de um texto. Nesse sentido, parece lícito identificar uma dupla posição de sobredestinatário: à posição que consiste em dar crédito às cenografias instituídas nos textos corresponderia um sobredestinatário que aceita a lógica que rege as normas de funcionamento dos cursos de pós-graduação; em contrapartida, à posição que faz pouco caso dessas cenografias, uma posição de sobredestinatário que se mostra crítico em relação a essa mesma lógica.

Como justificativa das relações propostas, lembramos que fazer pouco das cenografias, desqualificando-as como saídas inviáveis diante da gravidade da situação colocada, implica reconhecer que a solução para problemas tão cruciais como a atividade de formação de pós-graduandos não virá com um passe de mágica, mas somente por meio do questionamento das condições que hoje dão o tom dessa atividade. Em outras palavras, significa reconhecer que, se as condições de trabalho do mundo acadêmico são difíceis, tal dificuldade é resultado de dispositivos que vêm sendo implementados pelas políticas governamentais, situação que pode - e deve - ser combatida. Por outro lado, apostar nessas mesmas cenografias como possíveis saídas para os embates colocados implica não questionar as opções que vêm sendo feitas para se manter o status quo, ratificando-se, desse mo-

\footnotetext{
${ }^{5}$ É importante ter em mente aqui que a presente crítica a esse dispositivo cenográfico que incentiva "soluções mágicas” estende-se à figura do orientador: no primeiro texto, é a perspectiva do orientador que rege a confecção do decálogo; no segundo, é ele quem pega a lâmpada mágica e a esfrega, fazendo surgir o gênio.

${ }^{6}$ A referência às marionetes como lugar de produção da comicidade é de Bergson (1983).
} 
do, as medidas que vêm sendo tomadas em tempos de práticas neoliberais, a exemplo das que se seguem:

- falta de investimentos reais que qualifiquem a educação básica;

- sintomas de que algo vai mal na graduação, a exemplo da não reposição de vagas deixadas por docentes que se aposentam, do êxodo de docentes para atuar exclusivamente nos cursos de pós-graduação, gerando uma consequente sobrecarga para aqueles que permanecem na graduação, etc.;

- explosão de contratos de professores a título precário para atendimento exclusivo a necessidades emergenciais de regência de turma, criando-se, desse modo, um hiato intransponível entre ensino e pesquisa;

- redução do tempo máximo de conclusão dos trabalhos de pós-graduação, em nome de um ideal de eficiência e sem que os atores do processo - alunos e professores ratifiquem a pertinência da medida;

- aumento da tensão na relação orientador-orientando em decorrência dos prazos exíguos que devem ser obedecidos, tendo em vista as perdas em cadeia que se verificam caso o orientando não consiga concluir a tempo sua tarefa (cancelamento da bolsa de estudos, decréscimo da pontuação do programa de pós-graduação, do prestígio do orientador nos órgãos de fomento, na instituição e entre os colegas);

- meritocracia que nem sempre tem seus critérios suficientemente explicitados, ou que naturaliza seus dispositivos de hierarquização;

- em consonância com a mesma lógica, instituição de dispositivos hierarquizantes de classificação de revistas, livros e eventos científicos, assim como estabelecimento de diferentes categorias de pesquisadores.

Diante do exposto, o que nos parece efetivamente preocupante é que as políticas neoliberais venham conseguindo se expressar a tantas vozes, isto é, que venham conquistando tantos aliados - inclusive no interior da própria universidade:

\footnotetext{
Importa reiterar que a universidade - e quando dizemos universidade, referimonos exatamente ao conjunto de atores que nela atua, incluindo docentes em regência de turma, em atividades de pesquisa, em diferentes posições dos quadros administrativos - vem fomentando um diálogo com os representantes das políticas neoliberais no mesmo tom com que estes lhe dirigem a palavra, contribuindo, desse modo, para reafirmar as expectativas de uma lógica de mercado que pretende cristalizar um único modo de ser eficiente e produtivo (ROCHA; ROCHA, 2004, p. 32).
}

Eis, desse modo, o desafio no momento: abrir espaço para uma produção polifônica na qual outros sentidos de produtividade e eficiência possam se atualizar.

\section{5 (In)conclusões}

Entendido como instância necessariamente presente em toda e qualquer forma de comunicação, caracterizando-se por compreender adequadamente e avaliar com precisão o que é dito, oferecendo sempre respostas apropriadas, o sobredestinatário é um conceito de grande produtividade, mas também de grande indefinição quanto a seu modo de operacionalização. Com efeito, Bakhtin nos indica que, mediante uma "análise profunda" das trocas verbais, sempre será possível apreender esse terceiro participante, deixando, porém, em aberto o caminho a ser seguido para tal fim. Assim é que diversas são as formas de enten- 
dimento e de operacionalização do conceito que vêm sendo legitimamente experimentadas. A título de exemplo, cito a opção de Bryzzheva (2006), que, no contexto da sala de aula, vê no sobredestinatário uma figura de apoio que assegura ao professor a pertinência de suas ações, ou ainda a posição de Midgley, Henderson e Danaher (2010), que postulam três diferentes funções dialógicas em relação à identificação de sobredestinatários em um diálogo: a evocação de um sobredestinatário, quando o falante se dirige a autoridades fisicamente ausentes; a legitimação pelo ouvinte do sobredestinatário evocado pelo falante; a escuta de sobredestinatários não explicitamente evocados pelo falante, mas que são identificados pelo ouvinte.

Neste artigo, minha opção foi chegar ao conceito bakhtiniano de sobredestinatário por intermédio da noção de cenografia, entendida segundo formulação de Maingueneau (1989). Assim é que, em função da atitude do interlocutor diante das cenografias presentes nos dois textos humorísticos que instituímos como córpus, pudemos depreender posicionamentos antagônicos de sobredestinatários em relação ao ideário neoliberal em educação: um sobredestinatário que ratifica o referido ideário e um sobredestinatário que dele se distancia. Cumpre-se, desse modo, uma das já mencionadas funções-chave do sobredestinatário - o poder de semioses indefinidas que garante a textos como o literário um interesse sempre renovado -, com uma única diferença: ao invés de proporcionar leituras distanciadas no tempo ou no espaço, o que se atualiza em nosso córpus são diferentes posicionamentos discursivos que desfrutam de uma maior ou menor contiguidade espaçotemporal.

Uma última - porém não menos importante - reflexão. Diante do antagonismo de figuras de sobredestinatário que ora se manifestam - o que dá sustentação às iniciativas neoliberais e o que as rejeita -, que perfil de sobredestinatário vimos privilegiando em nossas práticas cotidianas? Afinal, ratificando a perspectiva bakhtiniana da responsividade dos textos, diremos que, se práticas neoliberais vêm-se afirmando, isto se explica certamente pelo fato de estarem sendo fortalecidas pelas ressonâncias que encontram em nossas próprias palavras. O que significa dizer: até que ponto temos alimentado o que se vem construindo hegemonicamente como sentido de "excelência", "produtividade" e "autonomia"? Com que tipo de (terceiro) parceiro - esse ouvinte ideal que é o sobredestinatário - temos feito aliança?

Se é fato que não podemos evitar o diálogo com nossos interlocutoresdestinatários representantes da lógica de mercado, não seria possível desqualificar a imagem de um sobredestinatário que guardasse esse mesmo perfil, instituindo novas bases de interlocução? (ROCHA; ROCHA, 2004, p. 34).

O cotidiano da academia pode, com efeito, ser penoso. O que não faz senão recolocar o desafio da invenção de novas práticas que tornem possível "surfar no laboratório".

\section{REFERÊNCIAS}

AMORIM, Marília. O pesquisador e seu outro: Bakhtin nas Ciências Humanas. 1. ed. São Paulo: Musa, 2001. 304 p.

BAKHTIN, Mikhail. Estética da comunicação verbal. 1. ed. São Paulo: Martins Fontes, 1992. 421 p.

BERGSON, Henri. O riso: ensaio sobre a significação do cômico. 2. ed. Rio de Janeiro: Zahar Editores, 1983.

BOURDIEU, Pierre. A essência do neoliberalismo. Le Monde diplomatique, mar. 1998. Disponível em: <http://riscos.no.sapo.pt/A\%20essencia\%20do\%20neoliberalismo.pdf>. Acesso em: 13 jan. 2013. 
BRYZZHEVA, Lyudmila. Superaddressee or who will succeed a mentor? Studies in Philosophy and Education, v. 25, p.227-243. 2006.

CLOT, Yves. L'auto-confrontation croisée en analyse du travail: l'apport de la théorie bakhtinienne du dialogue. In: Filliettaz; L.; Bronckart et J. P. (Dir.) L'analyse des actions et des discours en situation de travail. Louvain La Neuve: Peeters, 2005.

FARMER, Frank. Landmark essays on Bakhtin, rhetoric and writing. New Jersey: Lawrence Erbaum Associates, 1997.

MAINGUENEAU, D. Análise de textos de comunicação. São Paulo: Cortez, 2001.

MAINGUENEAU, D. Novas tendências em análise do discurso. Campinas, SP: Pontes, 1989.

MANCEBO, Deise; ROCHA, Marisa Lopes da. Avaliação na educação superior e trabalho docente. Interações, São Paulo: Unimarco, v.7I, n. 13, p. 55-75, jan./jun. 2002.

MANCEBO, Deise; ROCHA, Marisa Lopes da. Práticas neoliberais na universidade: reflexões sobre a formação em psicologia/educação. Psicologia da educação, São Paulo: Educ, n. 10/11, p. 155-167, 2000.

MIGDLEY, Warren; HENDERSON, Robyn; DANAHER, Patrick. Seeking superaddressees: research collaboration in a doctoral supervisory relationship. Disponível em: <eprints.usq.edu. au/9173/1/Midgley_Henderson_Danaher_Ch7_AV.pdf $>$. Acesso em: 19 jan. 2010.

MORSON, Gary Saul; EMERSON, Caryl. Mikhail Bakhtine. California: Stanford University Press, 1990.

ROCHA, Décio; DEUSDARÁ, Bruno. Coletivos de trabalho, espaços de discussão e avaliação docente em programas de pós-graduação stricto sensu. Eutomia, Recife: UFPE; Ed. 8, 2011.

ROCHA, Marisa Lopes da; ROCHA, Décio. Produção de conhecimento, práticas mercantilistas e novos modos de subjetivação. Psicologia e Sociedade: Revista da Associação Brasileira de Psicologia Social, v.16, n. 1, ed. especial. São Paulo: ABRAPSO, 2004.

SCOTT, Russell P. Pontos críticos e poder convergente no processo de orientação: fábulas, casos, palcos e bastidores. Ilha, Florianópolis, v. 6, n. 1/ 2, p.165-183, 2004.

SILVA JÚNIOR, João dos Reis; SGUISSARDI, Valdemar. Reconfiguração da educação superior no Brasil e redefinição das esferas pública e privada nos anos 90. Revista Brasileira de Educação, São Paulo: ANPED, n. 10, p. 33-57, jan./abr. 1999.

Recebido em fevereiro de 2013.

Aprovado em abril de 2013. 